\title{
Absolute Population Censuses of Cave-Dwelling Crickets: Congruence Between Mark-Recapture and Plot Density Estimates.
}

\author{
Gianmaria Carchini*, Mauro Rampini* and Valerio Sbordoni*
}

\author{
SUMMARY
}

The absolute size, $\mathrm{N}$, of a Dolichopoda geniculata population was estimated both by the Lincoln-Petersen index and the tctal count on sample plot methods in a natural cave in Central Italy. 19 pairs of estimates, obtained over 2 years, exhibit a seasonal pattern and a mean value of $\mathrm{N} \approx 430$. Differences between estimates obtained with the 2 methods are not significant $(P>0.8)$. These results, and data from the literature enable most of the major factors infuencing the two types of estimates to be identified. Respective cases where methods may be preferably applied are suggested.

\section{INTRODUCTION}

It has often been stressed that cave environments are ideal for certain areas of ecological research because of several intrinstic characteristics such as stability of abiotic factors, community simplicity and small populations (Poulson and White, 1969; Sbordoni, 1982; Howarth, 1983). Several researches have, in fact, studied ecology, genetics and evolution using cave populations. In many of these studieds, one of the fundamentally important parameters is absolute population size, N (Culver, 1982; Sbordoni, 1982).

Estimating $\mathrm{N}$ for cave-dwelling populations, has been the subject of several works over recent years. Today, by far the most widespread is the simple Lincoln-Petersen mark-recapture method (Mitchell, 1970a and 1970b; Peck, 1975; Keith, 1975; Cooper, 1975; Delay, 1975; Mitchell, Russel \& Elliot, 1977; Alvarez et al., 1981; Van Luik, 1981), some of the presuppositions of which seem more likely to be true for caves than for other environments. Other, less commonly used methods are: multiple mar-

* Istituto di Zoologia della Università degli Studi di Roma, Viale dell’Università 32, I . 00185, ROMA - ITALY. 
king (Hobbs, 1981) and actual count over a whole area (Bouvet et al., 1972).

Unfortunately, however, the true effectiveness of the methods used and their respective robustness to deviations from theoretical assumptions cannot be evaluated or deduced from the literature. Only two papers (Mitchell, 1970b; Delay, 1975) gave estimates for $\mathrm{N}$ obtained by separate and unrelated methods, and of the three populations sampled, only one provided values of $\mathrm{N}$ (obtained by two methods) that were in good agreement.

This paper reports on the congruence between estimates for $\mathrm{N}$ in a population of the cave cricket Dolichopoda geniculata (Costa) carried out over two years of observations.

The particular morphology of the cave selected for this study at Valmarino, Italy, enables both the Lincoln-Petersen and the plot density methods to be applied in optimal conditions.

\section{MATERIALS AND METHODS}

The study cave

The Valmarino cave is of natural origin, situated in Central Italy (Municipality of Monte San Biagio, Latina Province) is $15 \mathrm{~m}$ a.s.l. and $2 \mathrm{~km}$ from the coast. Of average size $(124 \mathrm{~m}$ long), it extends horizontally with flat floor, walls and ceiling which are poor in speleothems and other formations, owing to its particular sand lithology. Hence census-taking was facilitated by the internal form of the cave. Absence of fissures in the rock and the xerothermic climate of the surrounding area make it difficult for the eutroglophilic fauna to disperse from the cave. A detailed description of the cave and its community are to be found in: Carchini et al., (1982).

\section{The study population}

Dolichopoda are cave-dwelling crickets distributed throughout the Mediterranean Basin. Like other temperate Raphidophoridae, the may be considered as relicts of interglacial fauna from forest environments (Vandel, 1964). D. geniculata is to be found in central and southern parts of Italy and is constantly and abundantly present in cave communities. Natural cave populations have been found to be more strictly troglophilic than those colonizing man-made caves (Rampini et al., 1981).

The species has 6 preimaginal instars lasting for an approx. total of 1 year and an imago lifespan or about 6 months (Varricchio, 1935; Capolongo, 1966). All ages of D. geniculata are to be found in the Valmarino cave at all times and range in body size from 4.5 to $25 \mathrm{~mm}$. Furthermore, the $D$. geniculata 
population was seen to be distributed throughout the cave the year round.

\section{Density plot estimate}

The cave was mapped out by the traverse method using a measuring tape and transit compass. The internal surface area of the cave was estimated by measuring sequential cross sections no more than 2 meters high marked out along traverse sides. The measurements obatined were: floor surface area, 464 $\mathrm{m}^{2}$; wall and ceiling surface area, $1244 \mathrm{~m}^{2}$.

Inside the cave, counting plots of known area were established. After the first year of count, the area of counting plots was increased. During the first year, $341 \mathrm{~m}^{2}$ were kep t under observation; in the second year, $623 \mathrm{~m}^{2}$. All counting plots were located on walls and ceiling, because $D$. geniculata is rarely to be found on the floor at Valmarino cave. Calculations did not include floor area but assumed wall and ceiling surfaces as the only ones occupied. In the first year, this provided a ratio of observed surface/total surface, p, of 0.2741 and, in the second year, of 0.5008 .

Cricket counting was performed (prior to capture for marking) by 3 observers, who walked one way, from cave entrance to cave end, while a fourth person noted count results. Counting lasted no more than 60 minutes. According to the Seber (1973) method, population size was calculated $\mathrm{N}_{1}=\mathrm{N}_{\mathrm{O}} / \mathrm{p}$ and its variance by $\mathrm{V}\left[\mathrm{N}_{1}\right]=\mathrm{N}_{1} \mathrm{q} / \mathrm{p}$, were $\mathrm{N}_{\mathrm{O}}=$ number of crickets found in sampling area and $q=1-p$; confidence limits at $95 \%$ probability were calculated by $\mathrm{N}_{1}=1.96 \sigma$

\section{Mark-recapture estimate.}

Crickets to be marked were captured wherever found in the cave and enclosed, 10-20 at a time, in polythene bags. After capturing was completed, a small drop of paint in volatile solvent was painted on each individual, one at a time, on the prothorax. The very few crickets damaged by capture or marking were removed, the others were released after having waited a few seconds for the paint to dry.

Recapture was undertaken 48 hours later, using the same technique. Individuals were checked one by one for markings. Laboratory tests had shown that the survival rates of marked crickets are no lower than those for unmarked controls. As long as 5 months after marking, somes adult marked were seen in the cave to be engaged in normal activities, including mating.

Population size $\mathrm{N}_{2}$ was calculated using the Bailey (1951) modification of the Lincoln-Petersen Index, i.e. $\mathrm{N}_{2}=\mathrm{M}(\mathrm{T}+1) /$ $(R+1)$ were $M=$ number of marked individuals, $T=$ number 
of individuals caught the second day, $R=$ number of marked the first day and recaptured on the second. To calculate 95\% probability confidence limits, distribution of $\mathrm{N}_{2}$ was considered to be normal because $\mathrm{R} / \mathrm{M}$ and $\mathrm{R} / \mathrm{T}$ being greater than 0.1 on all occasions (Seber, 1973) and then the Bailey (1951) algorithm was used.

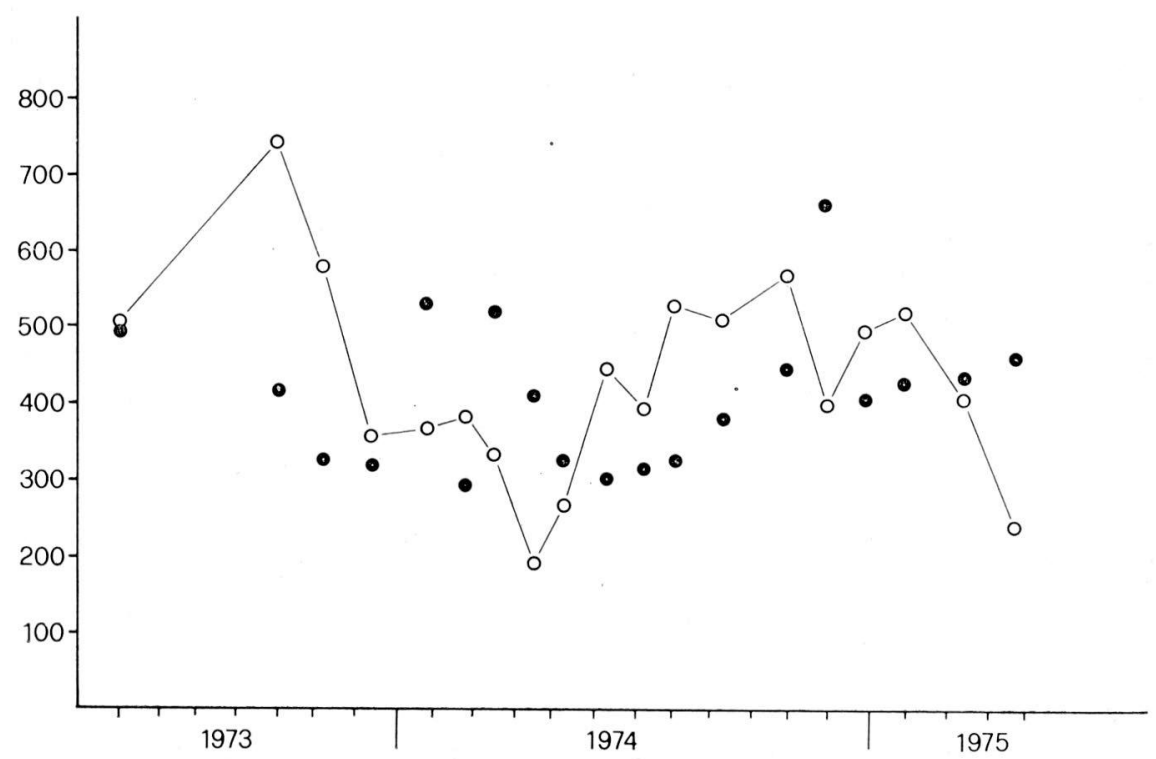

Fig. 1 - N vs. time. Solid circles, Lincoln-Petersen estimates of N; open circles, density plot estimates of $\mathrm{N}$.

\section{RESULTS}

All estimates of $\mathrm{N}$ refer to total population, regardless of age. During the two years of this investigation, 19 estimates were made using both methods. Results are reported in table 1 . The $95 \%$ Confidence ranges overlap 17 times out of 19 . Both methods exhibit substantial variations with time (Fig. 1). Nonetheless, plot density estimates, clearly exhibit a seasonal trend with minima in spring and maxima in autumn, whereas estimates using the mark-release method exhibit more erratic oscillations. Hence of the two methods, the plot density estimates seem more suitable, as was to be expected in view of the large proportion of the cave surface inspected for counting.

Significance of the differences observed between plot density and mark-recapture values was checked using the nonparame- 
Tab. 1 . Mark-recapture and plot density estimates. $\mathrm{N}_{\mathrm{O}}$, number of individuals counted within sample plots; $\mathrm{N}_{1}$, Lincoln-Petersen estimates of $\mathrm{N} ; \mathrm{N}_{2}$, plot density estimates of $\mathrm{N} ; \mathrm{M}, \mathrm{T}, \mathrm{R}, \mathrm{p}$, see text.

\begin{tabular}{cccccccccc}
\hline DATE & $\mathrm{M}$ & $\mathrm{T}$ & $\mathrm{R}$ & $\mathrm{N}_{1}$ & $95 \% \mathrm{C} . \mathrm{L}$. & $\mathrm{N}_{\mathrm{O}}$ & $\mathrm{P}$ & $\mathrm{N}_{2}$ & 95\% C.L. \\
\hline 26.05 .73 & 73 & 71 & 10 & 478 & $727 / 229$ & 145 & 0.2741 & 529 & $602 / 456$ \\
27.09 .73 & 88 & 78 & 15 & 434 & $619 / 250$ & 214 & 0.2741 & 781 & $870 / 692$ \\
28.10 .73 & 69 & 113 & 22 & 342 & $464 / 220$ & 166 & 0.2741 & 606 & $684 / 528$ \\
05.12 .73 & 76 & 99 & 21 & 345 & $470 / 221$ & 102 & 0.2741 & 372 & $433 / 311$ \\
15.01 .74 & 81 & 102 & 14 & 556 & $808 / 304$ & 104 & 0.2741 & 379 & $441 / 317$ \\
05.02 .74 & 133 & 112 & 48 & 307 & $371 / 243$ & 109 & 0.2741 & 398 & $462 / 334$ \\
07.03 .74 & 85 & 172 & 26 & 545 & $730 / 360$ & 95 & 0.2741 & 347 & $406 / 288$ \\
08.04 .74 & 82 & 72 & 13 & 428 & $622 / 233$ & 54 & 0.2741 & 197 & $245 / 149$ \\
27.04 .74 & 82 & 103 & 24 & 341 & $455 / 227$ & 76 & 0.2741 & 277 & $330 / 224$ \\
30.05 .74 & 96 & 84 & 25 & 314 & $412 / 215$ & 212 & 0.5008 & 423 & $489 / 357$ \\
27.06 .74 & 101 & 126 & 38 & 329 & $414 / 244$ & 182 & 0.5008 & 363 & $424 / 302$ \\
22.07 .74 & 87 & 108 & 27 & 339 & $445 / 232$ & 253 & 0.5008 & 505 & $577 / 433$ \\
29.08 .74 & 90 & 91 & 20 & 394 & $539 / 250$ & 188 & 0.5008 & 375 & $437 / 313$ \\
01.10 .74 & 108 & 145 & 33 & 464 & $598 / 329$ & 248 & 0.5008 & 495 & $566 / 424$ \\
18.11 .74 & 102 & 115 & 16 & 696 & $993 / 399$ & 241 & 0.5008 & 481 & $551 / 411$ \\
17.12 .74 & 146 & 121 & 41 & 424 & $527 / 321$ & 290 & 0.5008 & 579 & $656 / 502$ \\
14.01 .75 & 132 & 165 & 48 & 447 & $551 / 343$ & 246 & 0.5008 & 491 & $562 / 420$ \\
27.02 .75 & 133 & 122 & 35 & 454 & $578 / 331$ & 178 & 0.5008 & 355 & $415 / 295$ \\
08.04 .75 & 129 & 156 & 41 & 482 & $606 / 359$ & 155 & 0.5008 & 309 & $365 / 253$ \\
\hline mean & & & & 427.3 & & & & 434.6 & 133.8 \\
standard deviation \\
\hline
\end{tabular}


tric two-tailed Wilcoxon test and a two-tailed "t" test. Both tests are suitable for deviations from the normal (Salvi \& Chiandotto, 1978), expected in distribution of $\mathrm{N}$ because of observed seasonality. The first test gives $\mathrm{P} \gg 0.1$; the second test gives $\mathrm{P}>0.8$. Consequently, the null hypothesis that $\overline{\mathrm{N}}_{1}=\overline{\mathrm{N}}_{2}$ is to be considered as highly probable.

From the results presented, it may be concluded that the population of $D$. geniculata in the Valmarino cave was estimated well by with both methods used.

\section{DISCUSSION}

Using the Lincoln-Petersen method and quadrat sampling, Mitchell (1970b) estimated N for populations of Niptus abstrusus (Coleoptera: Ptinidae) and Dermestes carnivorous (Coleoptera: Dermestidae). With the first method, $\mathrm{N}$ for the N. abstrusus was found to be 14 times lower than the second method value. Of the two methods, Mitchell considered quadrat sampling to be more reliable, attributing error in the Lincoln-Petersen method to the low detectability of $N$. abstrusus which is $3-4 \mathrm{~mm}$ long. This, presumably, could have led to marked individuals being more likely to be recaptured than unmarked ones, thereby giving an under-estimate for N. This error would seem to be less substantial for $D$. carnivorous, which is $6-10 \mathrm{~mm}$ long, for which estimates of $\mathrm{N}$ using the two methods are really very similar.

Delay (1975) estimated $\mathrm{N}$ for a population of Speonomus longicornis (Coleoptera: Catopidae) with the Lincoln-Petersen method plus the counting of all individuals within the cave at one specific time. His estimated values of $\mathrm{N}$ according to the Lincoln-Petersen method are 13-97 times higher than those obtained by total capture. The author concluded that the population estimated with the Lincoln-Petersen method ranged over a greater subterranean habitat than that of the cave accessible to man and could not, therefore, truly coincide with the total number of beetles contained therein. The small size of the beetle (approx. $3 \mathrm{~mm}$ ) and long interval between marking and recapturing (between 14 and 200 days) could have enabled marked individuals to emigrate from the cave and into the developping network of cracks in the limestone body.

Keith (1975) estimated the density per square metre of Pseudanophtalmus tenuis (Coleoptera: Carabidae) using the Lincoln -Petersen method and counts within plots. The first method provided results from 1.9 to 14.2 times greater than the second. The author did not discuss the differences observed in terms 
of method reliability but considered both values to be valid and attributed them to a different distribution of individuals in relation to foraging patterns. It is, however, interesting to note that density estimates conducted within an area which is 6-8\% the size of the entire surface, do not provide good estimates of $\mathrm{N}$. Furthermore, the small size of the species (approx. $5 \mathrm{~mm}$ long) and its tendency to hide in cracks and under stones may have contributed to underestimating $\mathrm{N}$ by counting method.

Comparing the foregoing data with our results, the agreement in values for $\mathrm{N}$ for $D$. geniculata estimated by the two methods may possibly be due to the following factors: a) actual confinement within the cave of the study population; b) relatively detectability of marked and unmarked individuals; c) negligible births, deaths and molts between marking and recapture; d) sufficient mobility of the insects to enable random remixing of marked individuals with unmarked ones within a short period of time; e) count surfaces that are proportionally extensive and lack potential hiding places; f) accuracy in calculating cave surface areas.

Factors a), b), e) and f) influence density estimate whereas factors a), b), c) and d) affects accuracy of the mark-recapture method.

To conclude, it may be observed that:

1) Density estimate method accuraccy is, to a great extent, onditioned by cave morphology and, to a lesser extent, by the biological features of the species studied. Non-optimal experimental conditions lead to estimates that are not very imprecise. This method seems capable of giving the order of magnitude of $\mathrm{N}$ but precise estimation calls for considerable work in the field. This type of method does, in fact, seem more suitable to studies of artificial cave or guanophiles where definite quantities of guano can be found.

2) Mark-recapture results, on the other hand, appear to be influenced essentially by the species being investigated. Non-optimal experimental conditions may lead to largely imprecise estimates. These methods are, however, capable of producing estimates of $\mathrm{N}$ with a minor amount of field work and can be much more widely used in natural and man-made caves as long as the phenological and behavioral characteristics of the study species are known and appropriate for this form of census. From this point of view, Dolichopoda and other cave crickets seem to constitute highly suitable material for this type of investigation.

\section{REFERENCES}

ALVAREZ, C.V., M.N. OLIVIO and R.E. UROSA. 1981. Ecological analysis of terrestrial invertebrates in a venezuelan cave, Proc, Int, Congr. Spe- 
leol. 8th. Bowling Green, Ky. U.S.A.; 631-633.

BAILEY, N.T.J. 1951. On estimating the size of mobile populations from capture-recapture data. Biometrica, 38: 293-396.

BOUVET, Y., M.J. TURQUIN et E. MICHALON. 1972. Etude des biocoenoses du tunnel artificiel de Drom (Ain). Ann. Spéléol., 27:563-574.

CAPOLONGO D. 1966. Contributo alla conoscenza della entomofauna del Napoletano. Indagine ecologica e geonemica su Dolichopoda geniculata Costa. Boll. Soc. Ent. It., 96: 73-94.

CARCHINI, G., G. GIGLIO, M. RAMPINI, V. SBORDONI. 1982. Studi ecologici nella grotta di Valmarino. I: morfologia, clima, datazione e popolamento faunistico. Lavori della Società Italiana di Biogeografia. Nuova serie, 7: 869-892.

COOPER, J.C. 1975. Ecological and behavioral studies in Shelta Cave, Alabama, with emphasis on decapod crustaceans. $\mathrm{Ph}$. D. dissentation, University of Kentucky.

CULvER, D.C. 1982. Cave life. Harvard Univ. Press, Cambridge, Mass.

DELAY, B. 1975. Etude quantitative de populations monospecifiques de coléoptères ipogés par la méthode des marquages et recaptures. Ann. Spéléol., 30: 195-206.

HOBBS, H.H. III. 1978. Studies on the cave crayfish, Orconectes inermis inermis Cope (Decapoda, Cambaridae). Part. IV: Mark-recapture procedure for estimating population size and movement of individuals. Int. J. Speleol., 10:303-322.

HOBBS, H.H. III. 1981. Investigation of the troglobitic crayfish Orconecies inermis testii (Hay) in Mayfield's cave, Monroe County, Indiana. Int. J. Speleol., 11: 21-32.

HOWARTH, F.G. 1983. Ecology of cave arthropods. Ann. Rev. Entomol., 28: 365-389.

KEITH, J.H. 1975. Seasonal changes in a population of Pseudoanophthalmus tenuis (Coleoptera, Carabidae) in Murray Spring Cave, Indiana. A preliminary report. Int. J. Speleol., 7:33-44.

MITCHELL, R.W. 1970a. Population size and species association of mexican cavernicole Ricinuleid. Ciencia, 27 (2-3): 63-64.

MITCHELL, R.W. 1970b. Total number and density estimate of some species inhabiting Fern Cave, Texas. Ann. Spéléol., 25:73-90.

MITCHELL, R.W., W.H. RÚSSEL \& W.R. ELLIOT. 1977. Mexican eyeless characin fishes genus Astianax: environment, distribution and evolution. Special pubblication, The Museum, Texas Tech. University, N. 12.

PECK, S.B. 1975. A population study of the cave beetle Ptomaphagus loedingi (Coleoptera: Leiodidae, Catopinae). Int. J. Speleol., 7: 19-32.

POULSON, T.L. and W.B. WHITE. 1969. The cave environment. Science, 165: 971-981.

RAMPINI, M., G. CARCHINI e V. SBORDONI. 1981. Struttura e dinamica di popolazioni di Dolichopoda geniculata (Costa) in due grotte laziali. Atti XLVIII Convegno U.Z.I., Boll. Zool., 48 (suppl.): 93.

SAlvi, F., B. CHIANDOTTO. Biometria. Piccin, Padova.

SBORDONI, V. 1982. Advances in speciation of cave animals, p. 219-240. In C. BARIGOZZI (ed.) Mechanism of speciation. Alan R. Liss, Inc. New York.

SEBER, G.A.F. 1973. The estimation of animal abundance. Griffin. London.

VANDEL, A. 1964. Biospéologie: la biologie des animaux cavernicoles. Paris, Gauthier-Villars.

VAN LUIK, S.C. 1981. Ecology of crayfishes from West Virginia caves. Proc. Int. Congr. Speleol. 8th Bowling Green, Ky, U.S.A.,: 657-658.

VARRICCHIO, P. 1935. Note sulla morfologia e lo sviluppo post-embrionale della Dolichopoda palpata Sulzer. Annuario del Museo Zoologico della R, Università di Napoli (nuovạ șerie), 6 (19): 1-20, 